\title{
Intracellular Electrical Activity in Human Urinary Bladder Smooth Muscle: The Effect of High Sucrose Medium
}

\author{
Anna J. Visser Ron van Mastrigt \\ Department of Urology-Urodynamics, Erasmus University Rotterdam, The Netherlands
}

\section{Key Words}

Detrusor · Force · Electrophysiology · Action potential

\begin{abstract}
Introduction: The primary key to pharmacotherapy of bladder instability is in the excitation-contraction coupling of detrusor smooth muscle cells. To study this process, simultaneous recordings of mechanical and electrical activity are required. However, recording of mechanical activity induces movement, which may affect the quality of intracellular recordings. Materials and Methods: We therefore compared the electrical activity of human detrusor smooth muscle cells in normal Krebs' solution and in a hypertonic solution, which immobilizes the tissue, enabling us to study the effect of movement on the membrane potential. Carbachol and $\mathrm{KCl}$ were applied to induce contractions. Results: Sucrose in the medium made the tissue rigid and abolished its movement, while the electrical response was not affected. When compared with recordings in normal Krebs' solution, the average resting membrane potential was not altered. However, the membrane potential was more stable, with far less spike-shaped potentials. The spikeshaped potential amplitude was larger, while the duration was decreased. Conclusions: Impairing the ability of
\end{abstract}

\section{KARGER}

Fax + 41613061234

E-Mail karger@karger.ch

www. karger.com
(C) 2001 S. Karger AG, Basel

0042-1138/01/0664-0205\$17.50/0

Accessible online at:

www. karger.com/journals/uin tissue movement resulted in changes in the electrophysiological properties of detrusor smooth muscle cells. The results suggest that stretch has an effect on L-type $\mathrm{Ca}^{2+}$ channels.

Copyright $(\subset) 2001$ S. Karger AG, Basel

\section{Introduction}

Urine is stored in the bladder at low pressure, to be expelled rapidly at a convenient moment. To accomplish this, the detrusor muscle must have a high compliance in the resting phase and be capable of generating a high pressure to initiate and maintain the flow of urine. In some individuals, however, detrusor muscle contractions occur during the storage phase. This may lead to involuntary urine loss, necessitating research into the mechanisms involved in the initiation of detrusor contraction. Electrophysiological techniques are tools to study the physiological basis of bladder disorders like instability and low compliance. Until now, most intracellular recordings have been made in animal preparations, mainly in the guinea pig [1-18] and some in rabbit detrusor [6, 8, 19].

There are very few published records of electrical activity recorded from intact urinary bladder smooth muscle of any large mammal, let alone humans, probably 
due to the fact that the detrusor muscle cells display continuous mechanical activity, and possess an extensive extracellular matrix containing collagen and elastin [20], which makes it exceptionally difficult to impale these cells. Apart from a few studies in human isolated detrusor cells [21, 22], only our group has performed intracellular electrophysiological recordings of human detrusor strips [23-25]. Reference studies are therefore lacking. The results we obtained in human studies differ from those obtained by others in animal studies. Differences between species in functional and contractile behavior of bladder muscle have been reported previously [26], however, there could also be another explanation.

To study the initiation of bladder contraction, we made simultaneous recordings of mechanical and electrical activity. In such experiments, movement of the muscle tissue might influence the electrophysiological recording. In guinea pig detrusor strips, most intracellular recordings have been performed in a solution made hypertonic by adding sucrose to the medium, which inhibits contractions [27].

In rabbit detrusor, there are considerable differences between the parameters of the action potentials recorded in normal Krebs' solution or high sucrose medium. In control medium, Ursillo [19] recorded spike potentials of varied size, shape and frequency without ever exceeding $0 \mathrm{mV}$. Similarly, in hypertonic solution [6], the spikes also showed considerable variation in shape. However this time, overshoot potentials of up to $18 \mathrm{mV}$ were recorded. These findings suggest that movement of the tissue may cause a difference in intracellular recordings. Our previous results in human detrusor resembled the results from Ursillo [19].

In the present study, we therefore compared the electrical activity of human detrusor smooth muscle cells in normal Krebs' solution and in a hypertonic solution, which immobilized the tissue, enabling us to study the effect of movement on the membrane potential.

\section{Materials and Methods}

\section{Biopsy Samples}

Detrusor biopsy samples were collected from 12 patients ( 3 women and 9 men) ranging in age from 49 to 88 years (mean: 69 years, SD: 13 years) with approval from the local ethical committee and informed consent. The patients were undergoing surgery for bladder or prostate cancer and the tissue was collected using either cold-cup biopsy forceps (transurethral biopsies) or at open surgery (radical prostatectomy). Immediately after excision, the samples were stored in $0.9 \% \mathrm{NaCl}$. Outside of the operating theater, this solution was replaced by modified Krebs' solution (in $\mathrm{m} M$ ): $1.8 \mathrm{CaCl}_{2} ; 1.2$
$\mathrm{MgSO}_{4} ; 118 \mathrm{NaCl} ; 4.7 \mathrm{KCl} ; 25.0 \mathrm{NaHCO}_{3} ; 1.2 \mathrm{KH}_{2} \mathrm{PO}_{4}$, and 11.0 glucose. By aerating the solution with a mixture of $95 \% \mathrm{O}_{2}$ and $5 \%$ $\mathrm{CO}_{2}$, the $\mathrm{pH}$ was adjusted to 7.4. The tissue was transported to the laboratory within $10 \mathrm{~min}$ after excision, pinned down on Sylgard 184 (Dow Corning, Ithaca, N.Y., USA) and a muscle bundle about $2 \mathrm{~mm}$ long and $0.3 \mathrm{~mm}$ wide was dissected. Four of the biopsy samples were stored at $4{ }^{\circ} \mathrm{C}$ overnight before a muscle bundle was dissected. Connective tissue was removed mechanically.

\section{Electrophysiological Recordings}

All 12 biopsies were first tested for viability with carbachol (CCh) in normal Krebs' solution. Subsequently, from 6 biopsies recordings were made in normal Krebs' solution, and from 6 others in Krebs' solution made hypertonic with $15 \mathrm{~g}$ sucrose per $100 \mathrm{ml} \mathrm{Krebs'} \mathrm{solu-}$ tion to abolish movement [6]. One side of the muscle bundle was pinned down in a 4-ml recording chamber with a Sylgard 184 bottom on the stage of an inverted microscope (magnification $\times 40$; Zeiss) which was gradually heated to $35^{\circ} \mathrm{C}$ using a modified thermostat. The free part of the muscle bundle was connected to the forceps of a force transducer (BAM4C, Scientific Instruments, Heidelberg, Germany). The muscle bundle was stretched minimally to enable microelectrode recordings.

Intracellular recordings were made using borosilicate glass microelectrodes with a flexible tip $(\mathrm{GC} 120 \mathrm{~F}$, Clark Electromedical Instruments, Pangbourne Reading, UK). Filled with $3 \mathrm{M} \mathrm{KCl}$, the electrodes had 40-60 $\mathrm{M} \Omega$ resistance. They were placed in an $\mathrm{Ag} /$ $\mathrm{AgCl}$ pellet microelectrode holder connected to the input stage of a high impedance capacitance-neutralizing amplifier (World Precision Instruments, Sarasota, Fla., USA). An $\mathrm{Ag} / \mathrm{AgCl}$ electrode (outer diameter of $2.0 \mathrm{~mm}$ ) in an agar bridge served as the reference electrode in the organ bath. To minimize movement artifacts, the cells were speared in the longitudinal direction, at the side where the muscle bundle was pinned to the Sylgard. Penetration of a cell was considered successful when the reference potential rapidly shifted from zero to a more negative value of at least $-20 \mathrm{mV}$. At the end of the recording, when the tip of the electrode was no longer inside a cell, the value of the tip potential varied, if at all, less than $5 \mathrm{mV}$ from the zero level.

The electrophysiological signal was amplified 10 times and low pass filtered with a cutoff frequency of $1 \mathrm{kHz}$ (Krohn-Hite, Avon, Mass., USA). Both this signal and the signal from the force transducer were then $\mathrm{AD}$ converted at a sample rate of $2 \mathrm{kHz}$ (DAS1800, Keithley MetraByte, Taunton, Mass., USA) using a locally developed sampling program and digitally stored in a PC. The digitized force signal was filtered with a 4th-order Butterworth filter, using a cutoff frequency of $2 \mathrm{~Hz}$ to reduce the noise level. The shape of the signal was not affected by the filtering process.

The effect of $\mathrm{CCh}$ (Pharmachemie, The Netherlands) and $\mathrm{KCl}$ on the membrane potential were studied. Stock solutions of the substances were applied in random order to the bath in units of $0.01 \mathrm{ml}$, resulting in minimal bath concentrations of $3.4 \cdot 10^{-6} \mathrm{M} \mathrm{CCh}$ and $12.2 \cdot 10^{-3} \mathrm{M} \mathrm{KCl}$.

The bathing solution was refreshed constantly at $1.4 \cdot 10^{-2} \mathrm{ml} / \mathrm{s}$, renewing the bath contents within $5 \mathrm{~min}$. Difficulties with making long intracellular recordings were inherent to the type of preparation, therefore substances were often applied before total washout of the previous application. In those cases, the effective concentration was calculated using a standard concentration distribution formula. In the figure legends the final concentrations of the substances in the bath are given. 
Fig. 1. The response of human urinary bladder smooth muscle strips to application of $\mathrm{CCh}$ (left panels) and $\mathrm{KCl}$ (right panels) in control medium and high sucrose Krebs'. The upper panels represent the difference in force, the lower panels show the difference in membrane potential before and after stimulation. All values are means \pm SEM. ${ }^{*} \mathrm{p}<$ 0.05 and $* * \mathrm{p}<0.01$.

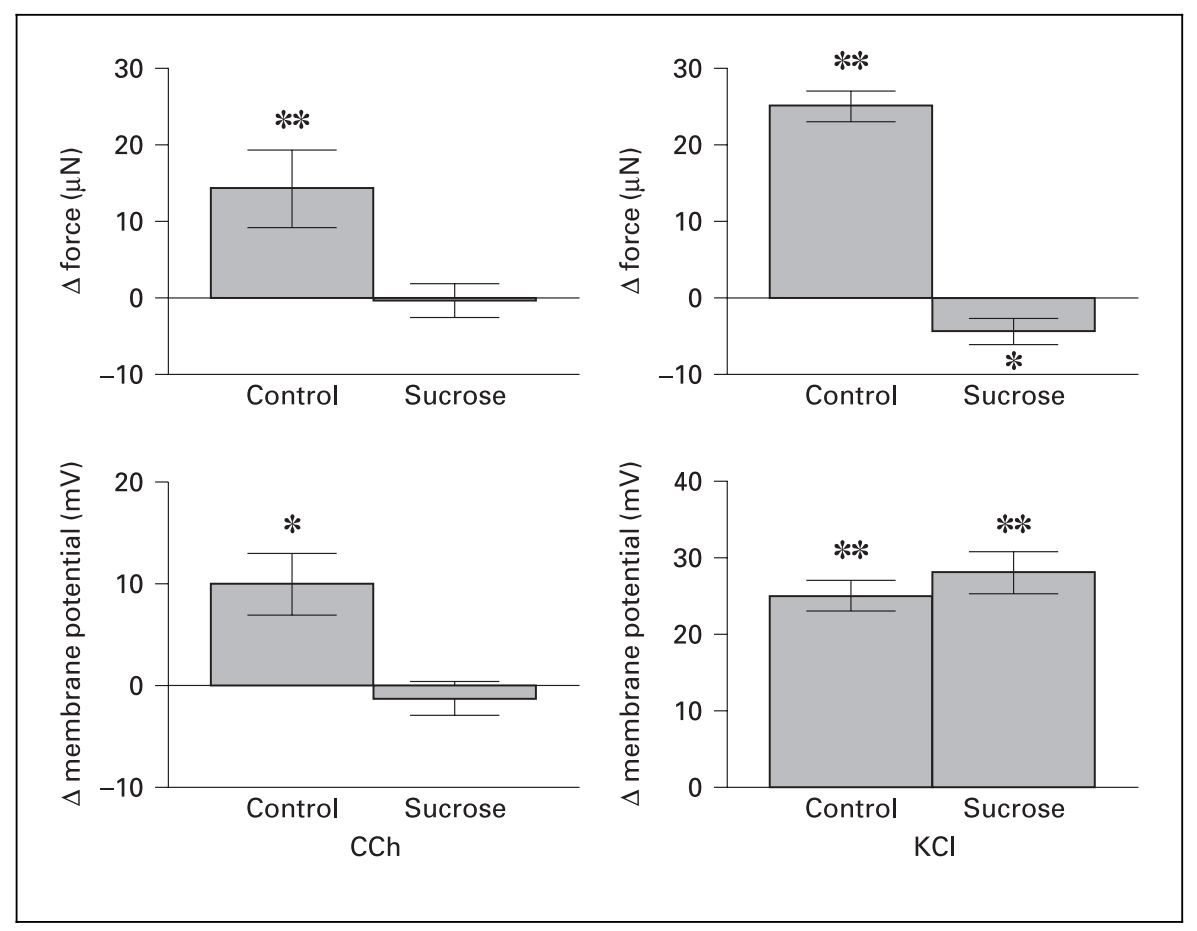

\section{Data Analysis}

The average resting membrane potential of the impaled cell, $\mathrm{V}_{\text {rest }}$, was calculated during $30 \mathrm{~s}$ before the stimulus. There was a clear maximal depolarization upon application of $\mathrm{KCl}$, in contrast to $\mathrm{CCh}$ application. Therefore, in the Results, the electrical response to $\mathrm{KCl}$ was specified in terms of the maximal depolarization. For $\mathrm{CCh}$, the response was noted as the average $V_{\text {rest }}$, calculated during $30 \mathrm{~s}$ immediately after stimulation. Resting membrane potential values more negative than $-100 \mathrm{mV}$ were sometimes recorded. These results were considered to be an artifact, most likely from bending of the electrode and were therefore excluded from further analysis.

There were spontaneous fluctuations from the resting membrane potentials in the form of spike-shaped potentials. The frequency of these events was determined in the same periods as the average resting membrane potential was determined, using especially developed software written in Matlab ${ }^{\circledR}$ 4.2c1 (Mathworks, Natick, Mass., USA), as described previously [23]. The following parameters characterizing these events were determined with a second program [23]: the amplitude was defined as the difference between the membrane potential value at the onset and the peak value of the event. The duration was calculated at $10 \%$ of the maximum amplitude $\left(\mathrm{d}_{10 \%}\right)$ to reduce the influence of noise. Negative duration values and amplitudes under $5 \mathrm{mV}$ were excluded from further analysis, since previous work showed that these were caused by incorrect parameter estimation [23]. This percentage of incorrect parameter estimation was $32 \%$ and similar to the ones in previous studies [23, 25]. Force values were read at the average level during 30 s preceding the stimulus and at the maximum after it. The calculated parameters were imported in Excel 5.0a. The Mann-Whitney U test and Wilcoxon's signed ranks test were done using SPSS 8.0 (SPSS, Chicago, Ill., USA).

Human Detrusor Electrical and Mechanical Activity

\section{Results}

\section{Force}

The average force level before the experiment was $217 \mu \mathrm{N}$ in the control group and $403 \mu \mathrm{N}$ in the sucrose group. This difference was not significant $(\mathrm{p}=0.699, \mathrm{n}=$ 12). Upon testing for viability in normal Krebs' solution, both groups responded with a significant force increase upon application of CCh $(\mathrm{p}=0.028, \mathrm{n}=6$ and $\mathrm{p}=0.028$, $\mathrm{n}=6$ ), and this response did not differ significantly between the groups $(\mathrm{p}=0.310, \mathrm{n}=12)$. The basal force level of both groups was higher when the experiment started and impalements of detrusor muscle cells were attempted. However, this effect did not reach the level of significance $(p \geq 0.116)$. The resting force level at the beginning of the experiment did not differ significantly between the control group and the sucrose group ( $\mathrm{p}=$ 0.093; $\mathrm{n}=12$ ).

During the experiment, application of $\mathrm{CCh}$ resulted only in a significant increase in force in control medium $(\mathrm{p}<0.001, \mathrm{n}=19)$, not in high sucrose medium $(\mathrm{p}=$ $0.763, \mathrm{n}=39$; fig. 1 left, upper panel). Also, application of $\mathrm{KCl}$ resulted in a significant increase in force level in normal Krebs' solution $(\mathrm{p}<0.001, \mathrm{n}=19$; fig. 1 right, upper panel). However, $\mathrm{KCl}$ application in medium containing sucrose caused no contractile response, but resulted in a 

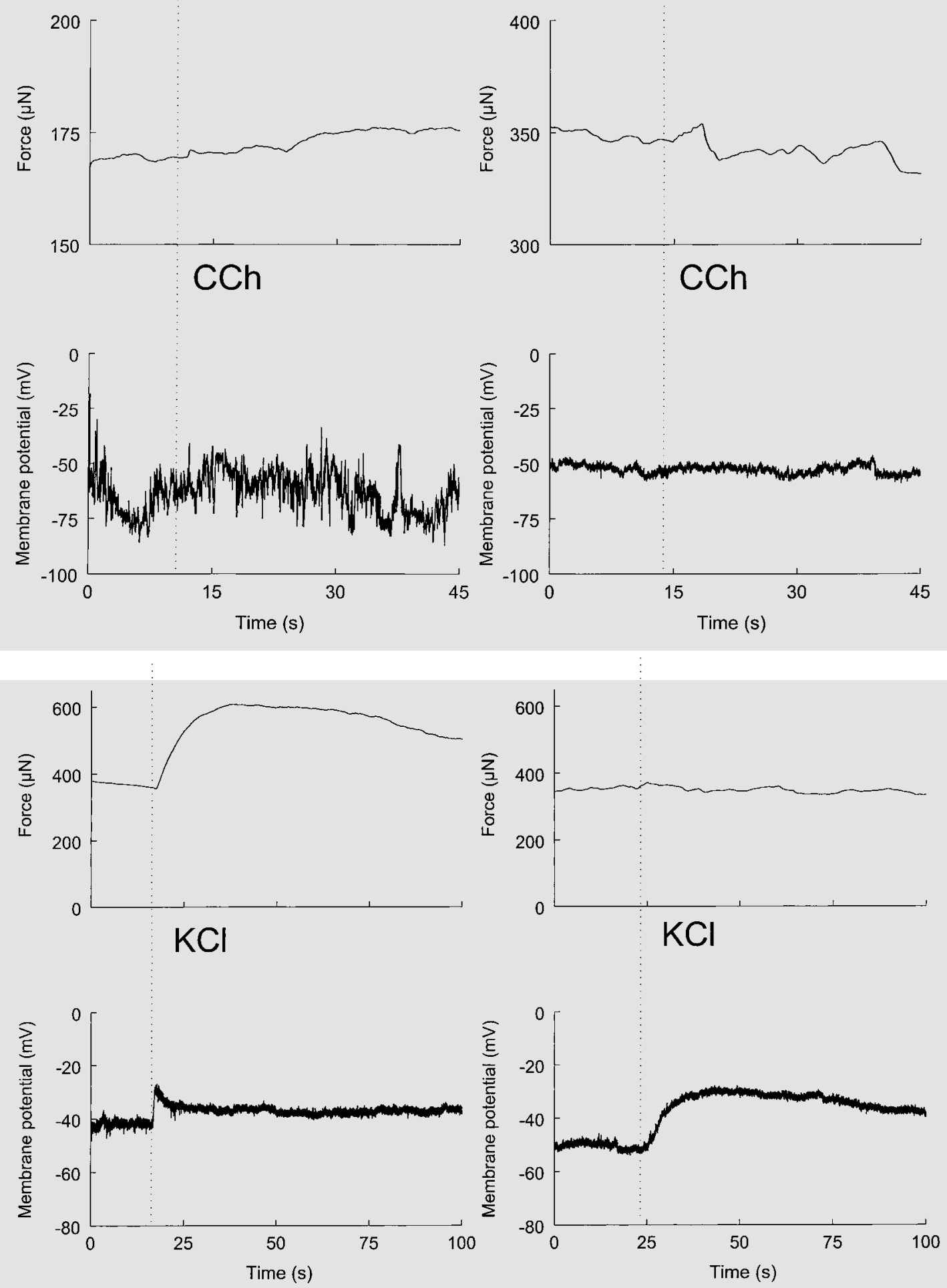

3

Fig. 2. Examples of CCh application in control Krebs' (left panels) and high sucrose medium (right panels). The concentration of CCh applied at the dotted line was $3.5 \cdot 10^{-6} \mathrm{M}$ in control medium and $4.3 \cdot 10^{-5} \mathrm{M}$ in high sucrose medium. Upper trace: force; lower trace: membrane potential.

Fig. 3. Examples of $\mathrm{KCl}$ application in control Krebs' (left panels) and high sucrose medium (right panels). The concentration of $\mathrm{KCl}$ applied at the dotted line was $12.2 \cdot 10^{-3} \mathrm{M}$ in control medium and $13.3 \cdot 10^{-3} \mathrm{M}$ in high sucrose medium. Upper trace: force; lower trace: membrane potential. 
Table 1. Spike-shaped potential parameters in human urinary bladder smooth muscle strips

\begin{tabular}{llrrr}
\hline Spike-shaped potentials & & Control & Sucrose & p value \\
\hline Amplitude (mV) & median & 9.7 & 12.0 & $<0.001$ \\
& I.Q.R. & 7.9 & 7.3 & \\
$\mathrm{~d}_{10 \%}, \mathrm{~ms}$ & median & 31.5 & 23.0 & $<0.001$ \\
& I.Q.R. & 58.0 & 15.5 & \\
Frequency, s & n & 1,501 & 2,086 & \\
& median & 0.40 & 0.02 & 0.001 \\
& I.Q.R. & 1.55 & 0.17 & \\
& n & 38 & 78 & \\
& & & &
\end{tabular}

The features of spike-shaped potentials and long-lasting depolarisations in human detrusor strips. The values of the median and interquartile range (I.Q.R.) or the amplitude, duration $\left(\mathrm{d}_{10 \%}\right)$ and frequency in control Krebs' and high sucrose medium are given.

small (mean $4 \mu \mathrm{N}$; SEM $2 \mu \mathrm{N})$ but significant $(\mathrm{p}=0.031$, $\mathrm{n}=39$ ) relaxation of the tissue (fig. 1 right, upper panel).

\section{Membrane Potential Recordings}

The average resting membrane potential, determined during $30 \mathrm{~s}$ before application of a stimulus, was $-55 \mathrm{mV}$ (SEM $4 \mathrm{mV} ; \mathrm{n}=38$ ) in control Krebs' and $-52 \mathrm{mV}$ (SEM $2 \mathrm{mV} ; \mathrm{n}=78)$ in high sucrose medium. These values did not differ significantly $(\mathrm{p}=0.881, \mathrm{n}=116)$.

Application of CCh resulted on average in a membrane potential depolarization of $10 \mathrm{mV}$ (SEM $4 \mathrm{mV}$; $\mathrm{p}=0.023$, $\mathrm{n}=19$ ) in control medium within $30 \mathrm{~s}$ (fig. 1 left, lower panel). In high sucrose Krebs' solution, there was no significant effect on the resting membrane potential $(\mathrm{n}=$ $0.763, \mathrm{n}=39$; fig. 1 left, lower panel). Figure 2 gives examples of CCh application in normal Krebs' solution (left panels) and in high sucrose medium (right panels).

In control Krebs' solution, the maximal response to $\mathrm{KCl}$ application was on average $25 \mathrm{mV}$ (SEM $3 \mathrm{mV}$; fig. 1 right, lower panel) and in high sucrose the depolarization was $28 \mathrm{mV}$ (SEM $3 \mathrm{mV}$; fig. 1 right, lower panel). Adding sucrose to the medium had no significant effect on the maximal depolarization in response to $\mathrm{KCl}$ application $(p=0.673, n=58)$. Figure 3 gives two typical examples of the response to $\mathrm{KCl}$ application in normal Krebs' solution (fig. 3 left panels) and in high sucrose medium (fig. 3 right panels).

In both media, the impaled cells displayed spontaneous activity in the form of spike-shaped potentials. In normal Krebs' solution, the median amplitude of the spike-shaped potentials was $10 \mathrm{mV}$ and overshoot poten-
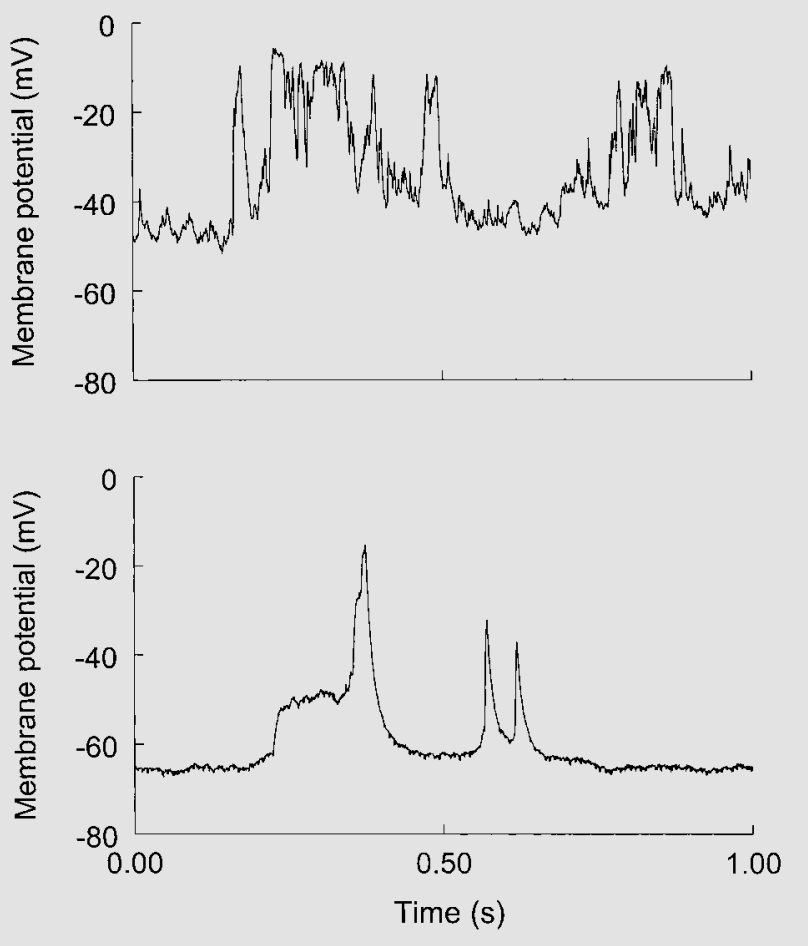

Fig. 4. Examples of spike-shaped potentials recorded in human urinary detrusor strips in control medium (top panel) and high sucrose Krebs' solution (bottom panel). Both traces are at the same scale.

tials were not recorded. Sucrose in the medium had a significant effect on the median amplitude and the duration of the spike-shaped potentials $\left(\mathrm{d}_{10 \%}\right.$; table 1$)$. The value of the amplitude increased by $2 \mathrm{mV}$ (table $1 ; \mathrm{p}<0.001, \mathrm{n}=$ 3,587 ) and the median value of the duration decreased by 9-23 ms (table 1; $\mathrm{p}<0.001, \mathrm{n}=3,587$ ). Also in high sucrose medium, spike-shaped potential amplitudes crossing $0 \mathrm{mV}$ were not registered. Figure 4 shows examples of spike-shaped potentials recorded in normal medium (fig. 4 top) and high sucrose Krebs' solution (fig. 4 bottom).

Adding $\mathrm{KCl}$ or $\mathrm{CCh}$ to the bath did not affect the frequency of the spike-shaped potentials in normal Krebs' solution ( $p \geq 0.284$ ) or in high sucrose medium ( $p \geq$ 0.091). The presence of sucrose in the medium itself, however, decreased the spike-shaped potential frequency $(\mathrm{p}=$ $0.001, \mathrm{n}=116$; table 1 ) . 


\section{Discussion}

Electrophysiological studies provide insight into the mechanisms involved in the initiation of detrusor contraction. Previously, we made simultaneous studies of force and membrane potential of human detrusor strips. These results differed from those obtained by other groups in animal studies. Most of those studies were performed in high sucrose medium, which abolishes tissue movement. Movement may affect the recordings of intracellular electrical activity. In this study we therefore compared electrical activity recorded in human detrusor muscle cells in a hypertonic solution, with recordings made in normal Krebs' solution.

In the hypertonic solution, the muscle strips appeared stiff and rigid. The force response to application of $\mathrm{CCh}$ or $\mathrm{KCl}$ disappeared in high sucrose medium. Application of $\mathrm{KCl}$ even resulted in a small relaxation of the tissue, while the membrane electrical response was unaltered. This relaxation was not a side effect of the application method, since a similar effect was not seen in response to the application of $\mathrm{CCh}$.

In both media, resting membrane potentials more negative than $-100 \mathrm{mV}$ were sometimes recorded. These values were resulting from artifacts, most likely bending of the electrode. This was not prevented by immobilizing the tissue with high sucrose. The average resting membrane potential was not significantly altered by the presence of sucrose in the medium. This was observed before in the rat detrusor [28].

The response to CCh was rather variable, but in this set of experiments, in contrast to our previous study [24], on average a small depolarization was seen in control conditions. This effect did not occur in high sucrose medium. The depolarization of the membrane potential upon $\mathrm{CCh}$ application in our control group could result from dislocation of the electrode by mechanical movement of the tissue, since the effect was lacking in high sucrose medium. However, depolarization due to $\mathrm{CCh}$ application has also been reported in high sucrose medium in guinea pig intracellular recordings $[13,17]$. CCh is an agonist of the muscarinic receptor, which is coupled to a second messenger system [29]. Therefore, activation of this system can produce contractions without changes in the membrane potential [8]. $\mathrm{KCl}$ induced a depolarization of the membrane potential in both groups of a similar magnitude.

In hypertonic solution, the electrical recordings resembled our earlier results in human detrusor strips more closely than the results obtained in animal models by other groups, although the resting membrane potential was more stable; the frequency of the spike-shaped potentials diminished. Meanwhile, the duration of these events decreased and the amplitude increased. This effect on amplitude and frequency has been observed before in guinea pig Taenia coli [27].

These results indicate the possibility that movement of the tissue affected the electrical activity of the cells. The more stable resting membrane potential and the reduced spike-shaped potential frequency could be explained by the reduced chance of dislocation of the microelectrode by movement of the tissue, which is more likely in normal Krebs' solution. Alternatively, stretch receptors present in the cell membrane may have been activated by movement. This type of receptors have been described in human detrusor smooth muscle tissue [30]. Dislocation of the microelectrode could easily explain a depolarization of the membrane, but not a change in the spike-shaped potential parameters, favoring the second hypothesis.

Sucrose had an effect on the spike-shaped potentials suggesting that stretch-operated receptors influence the opening time of the L-type $\mathrm{Ca}^{2+}$ channels.

In conclusion, making the Krebs' solution hypertonic by adding sucrose to the medium resulted in changes in the electrophysiological properties of detrusor smooth muscle cells. In the hypertonic solution, the tissue was rigid and mechanical activity was abolished. The ability to generate spike-shaped potentials and the general shape of these events were not affected. When compared with recordings in normal Krebs' solution, the membrane potential was more stable and the spike-shaped potential amplitude was larger, while the duration was decreased. The results suggest that stretch-operated receptors have an effect on L-type $\mathrm{Ca}^{2+}$ channels.

\section{Acknowledgements}

The authors thank Prof. Dr. Alison F. Brading for her valuable help and advice on the manuscript. The authors also thank the urologists of the University Hospital Rotterdam for providing the biopsy samples. This study was supported by the Dutch Kidney Foundation (C94.1370). 


\section{References}

1 Creed KE: Membrane properties of the smooth muscle membrane of the guinea-pig urinary bladder. Pflügers Arch 1971;326:115-126.

2 Creed KE: Effects of ions and drugs in the smooth muscle cell membrane of the guineapig urinary bladder. Pflügers Arch 1971;326: 127-141.

3 Kurihara S, Creed KE: Changes in the membrane potential of the smooth muscle cells of the guinea pig urinary bladder in various environments. Jpn J Physiol 1972;22:667-683.

4 Kurihara S, Sakai T: Relationship between effects of procaine and $\mathrm{Ca}$ on spontaneous electrical and mechanical activities of the smooth muscle cells of the guinea pig urinary bladder. Jpn J Physiol 1976;26:487-501.

5 Callahan SM, Creed KE: Electrical and mechanical activity of the isolated lower urinary tract of guinea-pig. Br J Pharmacol 1981;74: 353-358.

6 Callahan SM, Creed KE: Non-cholinergic neurotransmission and the effects of peptides on the urinary bladder of guinea-pigs and rabbits. J Physiol 1986;374:103-115.

7 Mostwin JL: The action potential of guinea-pig bladder smooth muscle. J Urol 1986;135: 1299-1303.

8 Fujii K: Evidence for adenosine triphosphate as an excitatory transmitter in guinea-pig, rabbit and pig urinary bladder. J Physiol 1988 ; 404:39-52.

9 Mostwin J: Electrical membrane events underlying contraction of guinea pig bladder muscle. Neurourol Urodyn 1988;6:429-437.

10 Foster CD, Fujii K, Kingdon J, Brading AF The effect of cromakalim on the smooth muscle of the guinea-pig urinary bladder. Br J Pharmacol 1989;97:281-291.
11 Fujii K, Foster CD, Brading AF, Parekh AB: Potassium channel blockers and the effects of cromakalim on the smooth muscle of the guinea-pig bladder. Br J Pharmacol 1990;99:779785.

12 Seki N, Karim OMA, Mostwin JL: Changes in electrical properties of guinea-pig smooth muscle membrane by experimental bladder outflow obstruction. Am J Physiol 1992;262:F885F891.

13 Seki N, Karim OMA, Mostwin JL: Effect of pinacidil on the membrane electrical activity of guinea-pig detrusor muscle. J Pharmacol Exp Ther 1992;263:816-822.

14 Creed KE, Callahan SM, Ito Y: Excitatory neurotransmission in the mammalian bladder and the effects of suramin. Br J Urol 1994;74:736743.

15 Hashitani H, Suzuki H: Electrical and mechanical responses produced by nerve stimulation in detrusor smooth muscle of the guinea-pig. Eur J Pharmacol 1995;248:177-183.

16 Bramich NJ, Brading AF: Electrical properties of smooth muscle in the guinea-pig urinary bladder. J Physiol 1996;492:185-198.

17 Hashitani H, Suzuki H, Kamazawa J: Effects of Y-26763, a novel K-channel opener, on electrical responses of smooth muscles in the guinea pig bladder. J Urol 1996;155:1454-1458.

18 Fry CH, Cooklin M, Birns J, Mundy AR: Measurement of intercellular electrical coupling in guinea-pig detrusor smooth muscle. J Urol 1999;161:660-664.

19 Ursillo RC: Electrical activity of the isolated nerve-urinary bladder strip preparation of the rabbit. Am J Physiol 1961;201:408-412.

20 Zimmern PE, Lin VK, McConnell JD: Smooth muscle physiology. Urol Clin North Am 1996; 23:211-219.

21 Inoue R, Brading AF: Human, pig and guineapig bladder smooth muscle cells generate similar inward currents in response to purinoreceptor activation. Br J Pharmacol 1991;103:1840_ 1841 .
22 Montgomery BSI, Fry $\mathrm{CH}$ : The action potential and net membrane currents in isolated human detrusor smooth muscle cells. J Urol 1992;147:176-184.

23 Visser AJ, van Mastrigt R: Intracellular recording of spontaneous electrical activity in human urinary bladder smooth muscle strips. Arch Physiol Biochem 1999;107:257-270.

24 Visser AJ, van Mastrigt R: Simultaneous recording of mechanical and intracellular electrical activity in human urinary bladder smooth muscle. BJU Int 2000;86:113-120.

25 Visser AJ, van Mastrigt R: The role of intracellular and extracellular calcium in mechanica and intracellular electrical activity of human urinary bladder smooth muscle. Urol Res 2000;28:260-268.

26 Sibley GNA: A comparison of spontaneous and nerve-mediated activity in bladder muscle from man, pig and rabbit. J Physiol 1984;354: 431-443.

27 Tomita T: Electrical responses of smooth muscle to external stimulation in hypertonic solution. J Physiol 1966;183:450-468.

28 Creed KE, Malmgren A: The effect of cromakalim on the electrical properties of and $\left[{ }^{86} \mathrm{Rb}^{+}\right]$ efflux from normal and hypertrophied rat bladder. Clin Exp Pharmacol Physiol 1993;20:215221.

29 Iacovou JW, Hill SJ, Birmingham AT, Bates $\mathrm{CP}$ : Calcium dependence and inositol phosphate accumulation in human detrusor smooth muscle. Neurourol Urodyn 1989;8:418-419.

30 Masters JG, Neal DE, Gillespie JI: Contractions in human detrusor smooth muscle induced by hypo-osmolar solutions. J Urol 1999; 162:581-589. 